\title{
Accessibility of headache centers for patients suffering for cluster headache in Italy: too far from the patients' needs
}

\author{
P Rossi ${ }^{1 *}$, C Geraci ${ }^{2}$, C Tassorelli ${ }^{3}$, G Nappi ${ }^{3}$ \\ From The European Headache and Migraine Trust International Congress \\ London, UK. 20-23 September 2012
}

\section{Background}

Due to the extraordinary severity of pain, cluster headache $(\mathrm{CH})$ warrants rapid diagnosis and appropriate treatment. The diagnosis of $\mathrm{CH}$ is simple, and rapid and effective treatments exist (injective sumatriptan and oxygen). In spite of this, clinical data have documented that $\mathrm{CH}$ is largely under-diagnosed and under-treated and it is common opinion that $\mathrm{CH}$ should be managed in a specialist setting. A fast access to headache services for $\mathrm{CH}$ patients is required to avoid delays to proper care. Aim of the study. To investigate the accessibility of the headache centers listed on the official websites of the two existing Italian societies involved into the study of headaches (SISC and ANIRCEF)

\section{Methods}

Volunteers suffering for $\mathrm{CH}$ and serving as active members of Alleanza Cefalalgici Cluster (AlCe Cluster) contacted the Italian headache specialists searching for a fast access to a visit or for talking with the physicians. The primary outcome measure was the fast access to the headache specialist, defined as an access scheduled within 7 days from the contact. The secondary outcome measures were a) the possibility to talk with the physicians and b) a service measure of call-center efficiency (number of calls necessary to be answered). The study was conducted on April 2012.

\section{Results}

151 headache centers were contacted in the study period. Fast access to a visit was allowed by 41 centres (31.7\%, 33 covered by the national health system and 15 in private practice; in 16 cases a special referral of the GP certifying the urgency was requested). Only 9 centres $(5.9 \%)$ gave to the patients the possibility to talk with the physician. 60 centres (39.7\%)did not answered to the call (at least 3 call per day at different times for 5 five days).

\section{Discussion}

The accessibility of headache centers for $\mathrm{CH}$ patients is inadequate and far from the patients' needs for an irrational organization and a bad use of the technical and human resources. An inacceptable disparity emerges between different geographical areas.

\section{Author details \\ ${ }^{1}$ Headache Centre INI Grottaferrata, Italy. ${ }^{2}$ AICe Cluster Europe, Germany. \\ ${ }^{3}$ IRCCS C Mondino Pavia, Italy.}

Published: 21 February 2013

\section{Reference}

1. Rozen TD, Fishman RS: Cluster Headache in the United States of America: demographics, clinical characteristics, triggers, suicidality, and personal burden. Headache 2011, May A. Cluster headache: pathogenesis, diagnosis, and management. Lancet 2005;366:843-855.

doi:10.1186/1129-2377-14-S1-P55

Cite this article as: Rossi et al:: Accessibility of headache centers for patients suffering for cluster headache in Italy: too far from the patients' needs. The Journal of Headache and Pain 2013 14(Suppl 1):P55.

${ }^{1}$ Headache Centre INI Grottaferrata, Italy

Full list of author information is available at the end of the article 